\title{
Development of adaptive seismic isolators for ultimate seismic protection of civil structures
}

\author{
Jianchun $\mathrm{Li}^{i^{*}}$, Yancheng $\mathrm{Li}^{1}$, Weihua $\mathrm{Li}^{2}$, and Bijan Samali ${ }^{1}$ \\ 1.Centre for Built Infrastructure Research, School of Civil and Environmental Engineering, Faculty \\ of Engineering and Information Technology, University of Technology Sydney, NSW 2007, \\ Australia \\ 2. School of Mechanical, Materials and Mechatronic Engineering, University of Wollongong, \\ Wollongong, NSW 2522, Australia
}

\begin{abstract}
Base isolation is the most popular seismic protection technique for civil engineering structures. However, research has revealed that the traditional base isolation system due to its passive nature is vulnerable to two kinds of earthquakes, i.e. the near-fault and far-fault earthquakes. A great deal of effort has been dedicated to improve the performance of the traditional base isolation system for these two types of earthquakes. This paper presents a recent research breakthrough on the development of a novel adaptive seismic isolation system as the quest for ultimate protection for civil structures, utilizing the field-dependent property of the magnetorheological elastomer (MRE). A novel adaptive seismic isolator was developed as the key element to form smart seismic isolation system. The novel isolator contains unique laminated structure of steel and MR elastomer layers, which enable its large-scale civil engineering applications, and a solenoid to provide sufficient and uniform magnetic field for energizing the field-dependent property of MR elastomers. With the controllable shear modulus/damping of the MR elastomer, the developed adaptive seismic isolator possesses a controllable lateral stiffness while maintaining adequate vertical loading capacity. In this paper, a comprehensive review on the development of the adaptive seismic isolator is present including designs, analysis and testing of two prototypical adaptive seismic isolators utilizing two different MRE materials. Experimental results show that the first prototypical MRE seismic isolator can provide stiffness increase up to $37.49 \%$, while the second prototypical MRE seismic isolator provides amazing increase of lateral stiffness up to $1630 \%$. Such range of increase of the controllable stiffness of the seismic isolator makes it highly practical for developing new adaptive base isolation system utilizing either semi-active or smart passive controls.
\end{abstract}

Keywords: Smart seismic isolation, ultimate protection, magnetorheological elastomer, civil structure

\section{INTRODUCTION}

Seismic base isolation is the most popular seismic protection technique against severe seismic events for civil engineering structures such as buildings and bridges ${ }^{1-3}$. It is a technique that mitigates the effects of earthquakes by essentially isolating the structure and its contents from potentially harmful ground motions, especially in the frequency range of which the structure is most affected. The practice of base isolation system received great popularity in United States, Japan as well as China during the last two decades ${ }^{4-7}$.

The implementation of the base isolation requires optimal design, which depends on the magnitude and frequency range of the designated earthquake that is considered ${ }^{4.7}$. As a result, a base isolation system, which is quite effective against one earthquake, may well be ineffective during another earthquake. Thus, adaptability of the base isolation systems emerges as a great concern for its application in the seismic prone regions ${ }^{8-10}$. Recent research reveals that the base isolation system is particularly vulnerable during the near-fault ${ }^{11-13}$ and far-fault earthquakes ${ }^{14-15}$. Near-fault earthquakes with a large displacement and long-period pulse, such as the 1994 North-ridge earthquake, lead to over-stretching the seismic isolator to exceed working range result malfunctioning of the systems ${ }^{11-13}$. While far-field earthquakes with a majority of low-frequency components that may fall into the resonant region of the conventional base isolation system, rather than helping reduce dynamic responses of the structure, which can result in amplification of destructive responses to the protected structures ${ }^{14-15}$.

In current base isolation practice, most of the seismic base isolated structures, either completed or still under constructions, use laminated rubber bearings ${ }^{1-3,16}$, including lead-core rubber bearings ${ }^{17}$ and high damping rubber

*Jianchun.li@uts.edu.au; phone +61 29514 2651; fax +61 295142633

Sensors and Smart Structures Technologies for Civil, Mechanical, and Aerospace Systems 2013, edited by Jerome Peter Lynch, Chung-Bang Yun, Kon-Well Wang, Proc. of SPIE Vol. 8692, $86920 \mathrm{H} \cdot$ (c) 2013 SPIE · CCC code: 0277-786X/13/\$18 - doi: 10.1117/12.2009626 
bearings ${ }^{18}$. For those rubber bearings, laminated structure is adopted which contains alternative rubber and steel layers vulcanized together to maintain large axial load-carrying capacity and relative small lateral stiffness [1-3, 16-18]. Traditional rubber is normally used in the bearing design to meet the performance requirements based on structural and geological conditions ${ }^{3}$. Once the designed and installed the base isolation system cannot change its property due to the passive nature of traditional rubber, which can be a problem when the installed seismic isolation system encounters different type of earthquake as aforementioned.

Addition of supplementary damping is one of the main techniques proposed to address this problem with aim to dissipate the external energy as well as keep the integrity of the seismic isolators in extreme events. A hybrid system ${ }^{19-23}$ was proposed by combining seismic base isolator with passive damping devices, such as viscous liquid damper, friction damper and metallic yielding damper. Smart base isolation ${ }^{8-9}$ system is also proposed by researchers through introducing active or semi-active damping device, such as piezoelectric friction damper and magnetorheological (MR) damper, into base isolation systems. However, supplementation of additional damping, whether passive, semi-active or active, will not change the natural frequency of the civil structure unless it is used to change the connectivity of the structure. Moreover, both the hybrid base isolation systems and current smart base isolation systems is complex for implementation and may potentially affect its cost, reliability and sustainability. It is therefore highly desirable if the lateral stiffness of the base isolation system, i.e. the elastic property of the base isolator, could be altered in a real time manner thus instantly decoupling any incoming external excitations (such as earthquakes) from the structures and contents to be protected.

A series of research efforts have been made by the authors for the past two years to utilize magnetorheological elastomer (MRE) to develop a novel adaptive seismic isolator ${ }^{28,29}$. MRE is a type of smart rubber, generally fabricated by dispersing magnetized particles in a solid polymer medium such as rubber ${ }^{24-25}$, to create its magnetic field dependent material properties. The elastic modulus or stiffness of MRE increases monotonically with the applied magnetic field. Upon removal of the magnetic field, the MRE immediately reverts to its initial status ${ }^{26-27}$. This unique and controllable stiffness property of MRE offers an opportunity for development of a new type of base isolators with a real-time controllability, which could potentially overcome the major shortcomings in the traditional base isolation systems ${ }^{28}$.

In this paper, research and development of two prototypes of adaptive seismic isolators are presented including design, fabrication and testing. Two different MRE materials, i.e. a normal MRE with shear modulus change from $0.1 \mathrm{MPa}$ (zero magnetic field) to $0.2 \mathrm{MPa}$ (magnetic field of $0.7 \mathrm{~T}$ ) and a soft $\mathrm{MRE}$ with shear modulus change from $4.73 \mathrm{KPa}$ (zero magnetic field) to $62.04 \mathrm{KPa}$ (magnetic field of $0.44 \mathrm{~T}$ ) are used for the two prototype isolators. Both adaptive base isolators have adopted the laminated structure of passive base isolation design in order to cope with large vertical loading in civil engineering applications. To achieve stiffness change adaptively, magnetic coils are used in the design to provide sufficient magnetic field for these prototypes. Experimental tests were conducted to evaluate performances of two adaptive base isolators under various loading conditions and magnetic field intensities.

\section{DESIGN OF ADAPTIVE SEISMIC ISOLATOR}

\subsection{Magnetorheological elastomers}

The materials used for the MREs in this investigation are: silicone rubber (Selleys Pty. LTD), silicone oil, type 378364 (Sigma-Aldrich Pty. LTD) and carbonyl iron particles, type C3518 (Sigma-Aldrich Pty. LTD). The density of silicone rubber, silicone oil and carbonyl iron particles are $1.04 \mathrm{~g} / \mathrm{cm} 3,0.96 \mathrm{~g} / \mathrm{ml}$ and $7.86 \mathrm{~g} / \mathrm{cm} 3$, respectively. The diameters of the iron particles are between $3 \mu \mathrm{m}$ and $5 \mu \mathrm{m}$. For the normal MRE material, the composition of the elastomer is silicone oil $10 \mathrm{~g}$, silicone rubber $20 \mathrm{~g}$ and carbonyl iron particles $70 \mathrm{~g}$, while for the soft MRE material the composition is silicone oil15 $\mathrm{g}$, silicone rubber $15 \mathrm{~g}$ and carbonyl iron particles $70 \mathrm{~g}$. Hence, the volume friction of the iron powder in the normal MRE and soft MRE are $30 \%$ and $22.9 \%$, respectively. The carbonyl iron particles were immersed in the silicone oil, and then were mixed with silicone rubbers. The mixture was put into a vacuum case to remove the air bubbles inside it, and then the mixture was poured into a mold for curing under constant magnetic field of 1.0T. The curing time for two MRE samples are 24 hours and 120 hours respectively.

Figure 1 shows the strain-stress curve of the normal MRE material in shear under various magnetic field strength. The MRE is a soft rubber-like material with $100 \%$ shear modulus change under the magnetic field of 0.7 Tesla, compared with that with absence of magnetic field. For $10 \%$ shear strain, the shear moduli are $0.1 \mathrm{MPa}$ and $0.2 \mathrm{MPa}$ with magnetic field of 0 Tesla and 0.7 Tesla, respectively. 
Figure 2 shows the shear stress - strain curves of soft MRE sample at 5 different magnetic flux densities ranging from 0 to $0.44 \mathrm{~T}$. In the shear stress-shear strain curve, the slope of the curve is the shear modulus of the material. Without magnetic field, the shear modulus of the soft MRE material is $4.73 \mathrm{KPa}$, while when the magnetic flux density is $0.44 \mathrm{~T}$, the shear modulus becomes $62.04 \mathrm{KPa}$. Therefore, the MR effect of this material induces more than $1300 \%$ increase on elastic modulus. It is also found that when the magnetic field is $1.0 \mathrm{~T}$, the MR effect of the material results in $2200 \%$ increase of elastic modulus.

As can be seen in figures 1 and 2, shear moduli of the MRE samples display an increasing trend with magnetic field, which proves that the MRE exhibits obvious MR effects. Within yield shear strain of both MREs, the shear stress and the shear strain exhibit a linear relationship for any given magnetic field. Beyond this critical strain, both materials display typical plasticity. The shear yield stress of MREs increase with increase of the applied magnetic field, demonstrating typical MR effects. For example, for soft MRE the shear yield stress increases from $10 \mathrm{kPa}$ to $27.5 \mathrm{kPa}$ while the critical shear strain decreases from $220 \%$ to around $30 \%$ when the magnetic field increases from 0 to $0.44 \mathrm{~T}$. Beyond the critical shear strain, the MRE behaves as plastic material. For the normal MRE sample 1, the shear yield stress vary from $18 \mathrm{kPa}$ to $40 \mathrm{kPa}$ while the critical shear strains are around $19 \%$ to $27 \%$ when magnetic field intensity increases from 0T to $0.7 \mathrm{~T}$. In the device design, it is desirable to accommodate in the linear state of the material. Therefore, MRE device containing soft MRE materials have larger allowable shear strain than that with harder MRE materials. In the meanwhile, due to its low shear stress and large adjustable range of soft MRE material, the MRE device containing such materials will have low lateral stiffness and weight capacity but with high adjustable range with same geometric configuration.

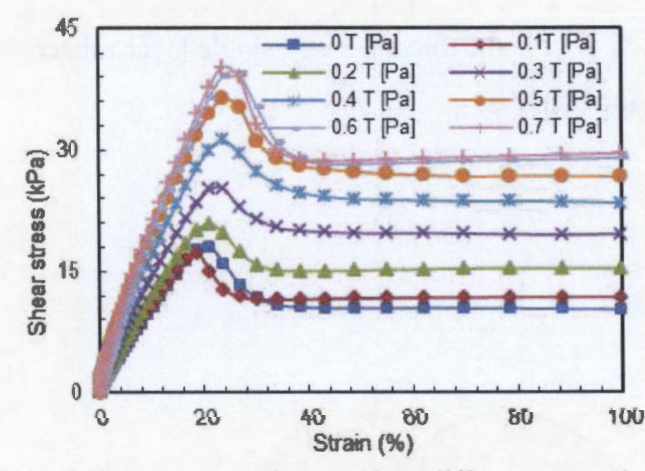

Figure 1 shear stress vs shear strain at different magnetic fields for MRE sample 1

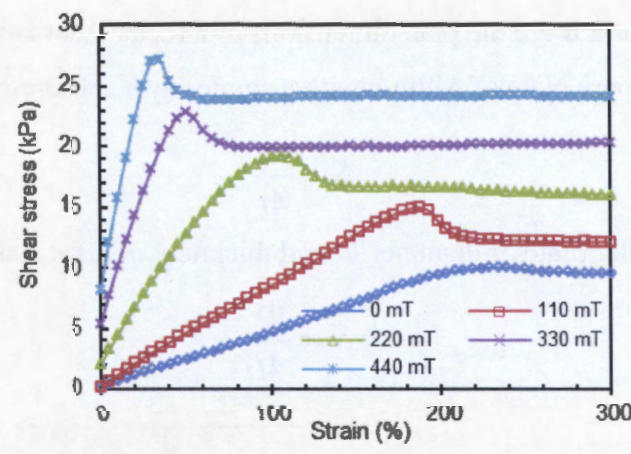

Figure 2 shear stress vs shear strain at different magnetic fields for soft MRE sample 2

\subsection{Adaptive seismic isolator design}

The configuration of the novel MRE seismic isolators, as shown in figure 8, incorporates the laminated structural design of traditional laminated rubber bearing ${ }^{1-3}$. It consists of multilayer thin MRE sheets bonded onto multilayer thin steel plates. In the prototypes, coils are placed outside of the laminated bearing element to provide magnetic field to the fielddependent MRE materials. The solenoid coil is made of copper wire and thin non-magnetic support as illustrated in figure 3. To further enhance the magnetic field in the isolator, a cylindrical steel yoke is designed and installed around the coil to form an enclosed magnetic circuit. To enable movement of the device, a small gap of $5 \mathrm{~mm}$ between the top plate and the steel yoke is allowed. Detailed design of the MRE seismic isolator can be referred to references ${ }^{28-29}$.

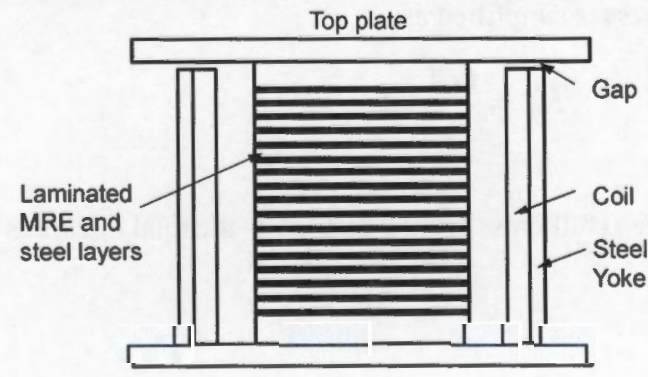

Figure 3 Cross section of the MRE seismic isolator 
In the design of the adaptive seismic isolator, two design parameters are crucial to both practical implementation and theoretical evaluation of its performances, i.e. vertical loading carrying capacity and lateral stiffness of the seismic isolator.

The weight capacity of the laminated base isolator is considered by the following calculation:

$$
W=A^{\prime} G S \gamma_{w}
$$

Where, $\boldsymbol{A}^{\prime}$ ' is the overlap of the top and bottom of the base isolator, named as the effective area, $\boldsymbol{G}$ is the shear modulus of the rubber, $S$ is the shape factor of a single layer of rubber; $\gamma_{w}$ is the allowable shear strain due to weight.

The shape factor $S$ is a non-dimensional measure of the aspect ratio of the single layer of the elastomer, defined as:

$$
S=\frac{A_{\text {lood }}}{A_{\text {load }- \text { free }}}
$$

Where, $\boldsymbol{A}_{\text {load }}$ is the area of the base isolator with load applied on, $\boldsymbol{A}_{\text {lood-free }}$ is the area of the base isolator without any load applied on.

For example, the shape factor $\boldsymbol{S}$ for a rectangular isolator is:

$$
S=\frac{L \times B}{2(L+B) t}
$$

Where, $L$ and $\boldsymbol{B}$ are the plan dimensions of a rectangular isolator, $L \leq B, t$ is the thickness of a single layer rubber.

So, in a square plate of width $a$ with a single-layer thickness $t$ the shape factor is,

$$
S=\frac{a}{4 t}
$$

For a circular plate of diameter $\boldsymbol{\Phi}$ and thickness of $t$, the shape factor is,

$$
S=\frac{\Phi}{4 t}
$$
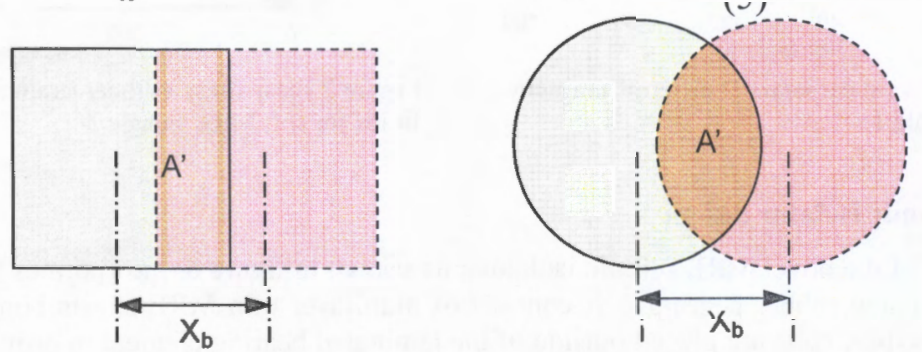

Figure 4. Effective area of the base isolator under maximum displacement

To analyze performance of a laminated base isolator, the isolator is usually approximated as a vertical shear beam, since the stiff steel layers severely inhibit flexural deformation while providing no impediment to shear deformation. Therefore, the horizontal stiffness is simplified as:

$$
K_{b}=\frac{G A}{h}
$$

Where, $\boldsymbol{A}$ is the rubber layer area (full cross section area), $\boldsymbol{h}$ is the total thickness of the rubber layer. 
Table 1. Structural parameters of two prototypical MRE base isolators

\begin{tabular}{|l|l|l|l|}
\hline Parameters & Prototype 1 & Prototype 2 & Unit \\
\hline Diameter of round rubber sheets & 140 & 120 & $\mathrm{~mm}$ \\
\hline Thickness of rubber sheets (each) & 2 & 1 & $\mathrm{~mm}$ \\
\hline Number of rubber sheets & 47 & 25 & \\
\hline Total thickness of rubber sheets & 94 & 25 & $\mathrm{~mm}$ \\
\hline Maximum designed displacement & 26 & 15 & $\mathrm{~mm}$ \\
\hline Maximum shear strain & 0.277 & 0.60 & \\
\hline
\end{tabular}

From Eq.(6) it is clear that in design low lateral stiffness can be achieved by decreasing the cross section area of the laminated structure or by increasing the thickness of the rubber layers. However, if the cross sectional area is not sufficient or the rubber layer is too thick, the isolator may become unstable when it is subject to sever vibrations while supporting a large vertical loading. Therefore, a optimization of these two parameters must be considered in the design process to retain the stability of the base isolator while maximize the performance of the isolator. The final design parameters of two prototype MRE seismic isolators are given in Table 1.

It is estimated that the prototype 1 MRE seismic isolator has a minimum vertical load carrying capacity of $280 \mathrm{~kg}$ under maximum designed shear displacement of $26 \mathrm{~mm}$ when there is no current applied to the MREs (the shear modulus of the MRE is $0.1 \mathrm{MPa}$ at 0 current). If increasing the applied current till the magnetic field reaches $0.7 \mathrm{~T}$, the loading capacity of the device will be increased up to $370 \mathrm{~kg}$ under maximum designed shear displacement. For prototype 2 MRE seismic isolator, the minimum loading carrying capacity is around $50 \mathrm{~kg}$ under maximum designed shear displacement of $15 \mathrm{~mm}$ when no current is applied to the MREs while the maximum load carrying capacity will increase to $655 \mathrm{~kg}$ under maximum designed shear displacement of $15 \mathrm{~mm}$ if the magnetic field inside the MRE material reaches its max $(0.44 \mathrm{~T})$ for the current design. When the shear displacement is less than maximum designed displacement, the vertical load carrying capacity of these isolators will be greatly increased.

As the loading capacity of the laminated isolators is highly dependent on the rubber material property, shape factor of the rubber layer, effective area of the isolator and the maximum allowable shear strain of the rubber, optimal design is needed based on the requirements of applications. For a specific design of the MRE seismic isolator, if the geometric configuration is given, the performance of the device is mainly dependent on the material property of the rubber, the range of shear modulus of the MRE under applied magnetic field. A MRE material with less silicon oil as mixture will provide higher initial shear modulus but less room for shear modulus change under applied magnetic field. The lateral stiffness of the isolator is highly dependent on the material property of the MREs, the size of the rubber pad and total thickness of the rubber material. The shape factor of the rubber does not have impact on the lateral stiffness. To achieve a low lateral stiffness, small rubber pad and large thickness of the rubber material are desirable. However, when total sum of the rubber thickness in the isolator become excessive, it jeopardizes the stability of the isolator when it supports a large vertical load. Therefore, trade-off among the initial vertical loading capacity, lateral stiffness requirement and the changing range of shear modulus should be carefully considered in the device design.

\section{EXPERIMENTAL SETUP}

Figure 5 shows a schematic illustration of the experimental setup for evaluation and characterization of two prototypical MRE seismic isolators and the actually experimental setup are shown in figure 6a) and $6 \mathrm{~b}$ ), respectively. In the experimental set-up, the shake table is used to provide horizontal loadings to the isolators either in the quasi-static mode or in dynamic mode. The MRE seismic isolator is mounted on the shake table and moves along with the shake table motion. A load cell is installed between the isolator and the reaction rig to measure the lateral load applied to the isolator. During the test, the top of the isolator and the load cell remains motionless thus eliminates any undesired inertia force contribution in the measurement. A DC power supply with capacity of $200 \mathrm{~V}$ and $8 \mathrm{~A}$ provides DC current to energize the magnetic coil of the MRE isolator. Since the dominant frequencies of the earthquakes are generally below 5 $\mathrm{Hz}$, the dynamic tests were designed with excitation frequencies ranging from 0.1 to $3 \mathrm{~Hz}$. Experimental parameters are detailed in table 2 . 


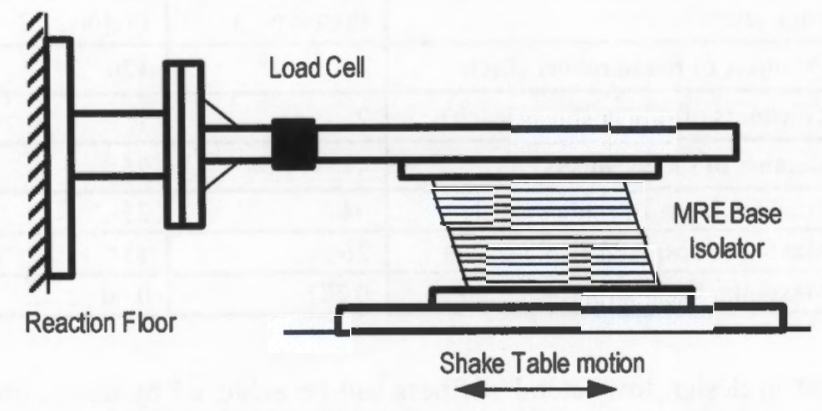

Figure 5 Sketch of the experimental setup

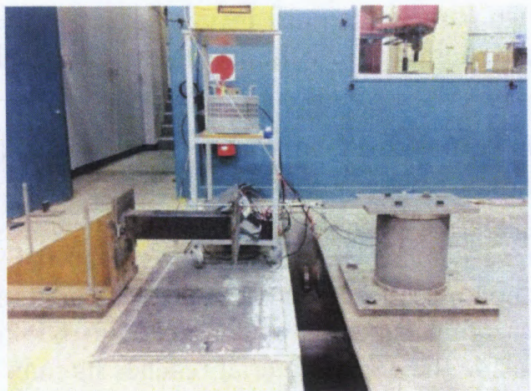

Figure 6 a) Test photo for MRE base isolator prototype 1

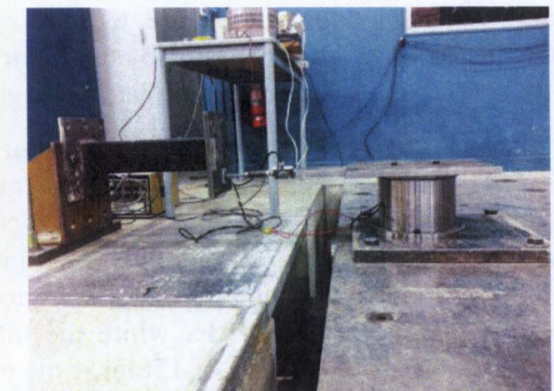

Figure 6 b) Test photo for MRE base isolator prototype 2

Table 2. Experimental parameters for two tests

\begin{tabular}{|l|l|l|}
\hline Parameters & Prototype 1 & Prototype 2 \\
\hline Electrical resistance of the coil & $32.3 \Omega$ & $42.3 \Omega$ \\
\hline Loading amplitude & $5 \mathrm{~mm}$ and $10 \mathrm{~mm}$ & $2 \mathrm{~mm}, 4 \mathrm{~mm}$ and $8 \mathrm{~mm}$ \\
\hline Loading frequency & $0.5 \mathrm{~Hz}, 1.0 \mathrm{~Hz}$ and $3.0 \mathrm{~Hz}$ & $0.1 \mathrm{~Hz}, 1.0 \mathrm{~Hz}, 2.0 \mathrm{~Hz}$ and $4.0 \mathrm{~Hz}$ \\
\hline Applied current & $0 \mathrm{~A}, 3 \mathrm{~A}$ and $5 \mathrm{~A}$ & $0 \mathrm{~A}, 1 \mathrm{~A}, 2 \mathrm{~A}$ and $3 \mathrm{~A}$ \\
\hline
\end{tabular}

\section{EXPERIMENTAL RESULTS}

Figure 7 shows the force measurement of the first prototypical MRE seismic isolator at sinusoidal loading with amplitude of $5 \mathrm{~mm}$ and frequency of $1.0 \mathrm{~Hz}$ for different applied currents, i.e. $0.0 \mathrm{~A}, 3.0 \mathrm{~A}$ and 5.0A. Figure 8 shows the force measurement of the second prototypical MRE seismic isolator at sinusoidal loading with amplitude of $2 \mathrm{~mm}$ and frequency of $1.0 \mathrm{~Hz}$ for different applied currents, i.e. $0.0 \mathrm{~A}, 1.0 \mathrm{~A}, 2.0 \mathrm{~A}$ and $3.0 \mathrm{~A}$. It is clearly observed that both prototypes exhibit obvious force increase with the increase of the applied current to MRE. Comparatively, the prototype 2 shows significant increase on the measured force while the prototype 1 exhibits moderate force increase. This is due to the respective material design of two MREs presently in section 2.1. Force-displacement loops of two MRE seismic isolators under dynamic loading with low frequency and moderate frequency excitations are demonstrated in Figure 9 and 10. The results also indicate that MR effect has been clearly obtained for both seismic isolators. In term of force increase and stiffness increase, prototype 2 isolator is superior to prototype 1. 


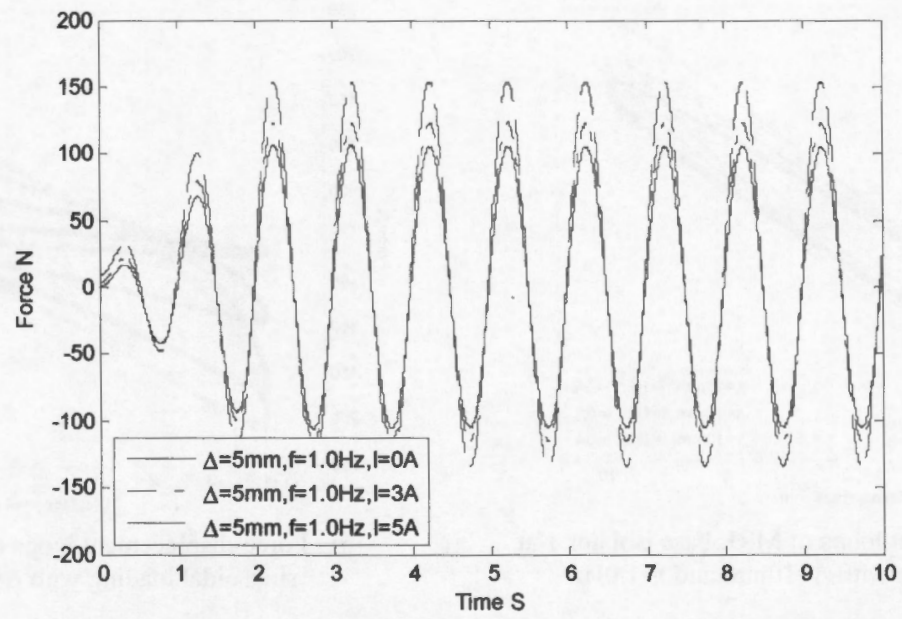

Figure 7 Force responses of the MRE seismic isolator 1 at sinusoidal loading with $\Delta=5 \mathrm{~mm}$ and $\mathrm{f}=1.0 \mathrm{~Hz}$

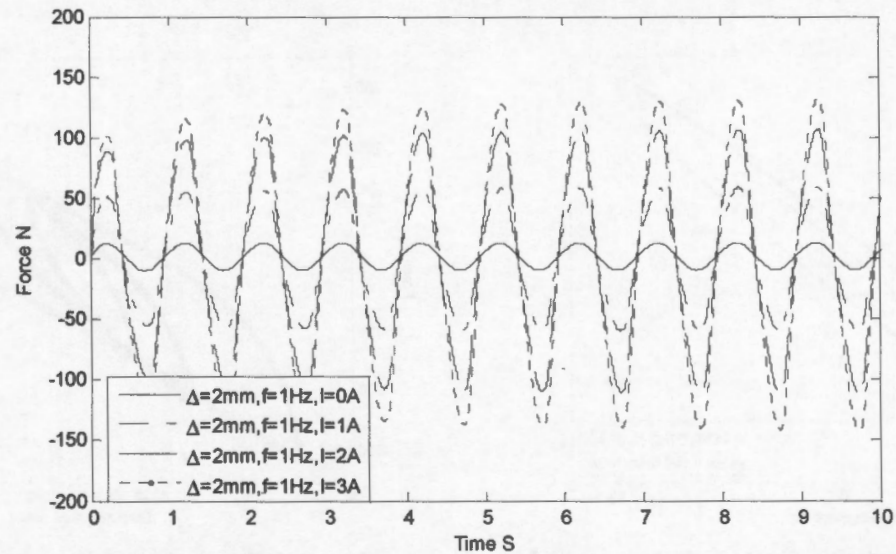

Figure 8 Force responses of the MRE seismic isolator 2 at sinusoidal loading with $\Delta=2 \mathrm{~mm}$ and $\mathrm{f}=1.0 \mathrm{~Hz}$

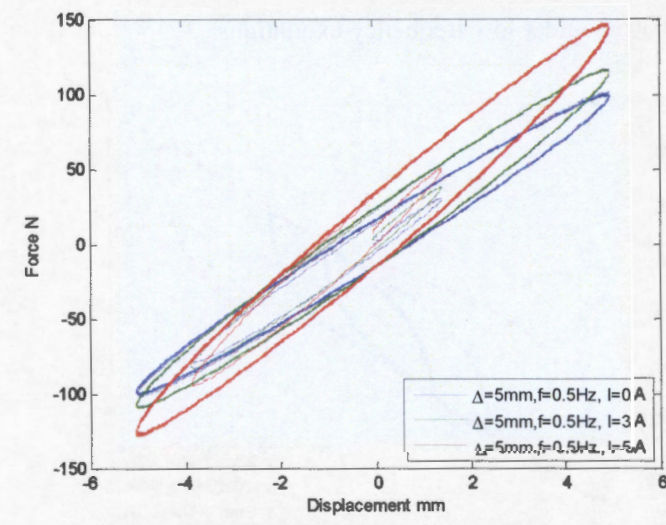

a) Force-displacement loops of MRE base isolator 1 at sinusoidal loading with $\Delta=5 \mathrm{~mm}$ and $\mathrm{f}=0.5 \mathrm{~Hz}$

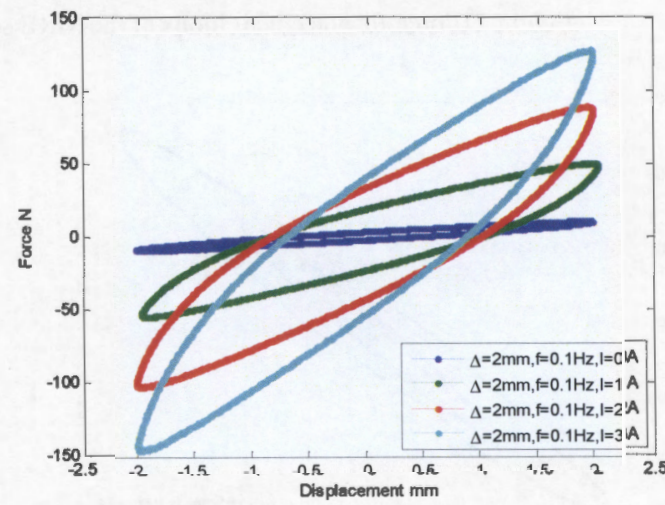

b) Force-displacement loops of MRE base isolator 2 at sinusoidal loading with $\Delta=2 \mathrm{~mm}$ and $\mathrm{f}=0.1 \mathrm{~Hz}$

Figure 9 Comparison between two MRE seismic isolator designs at low frequency excitations 


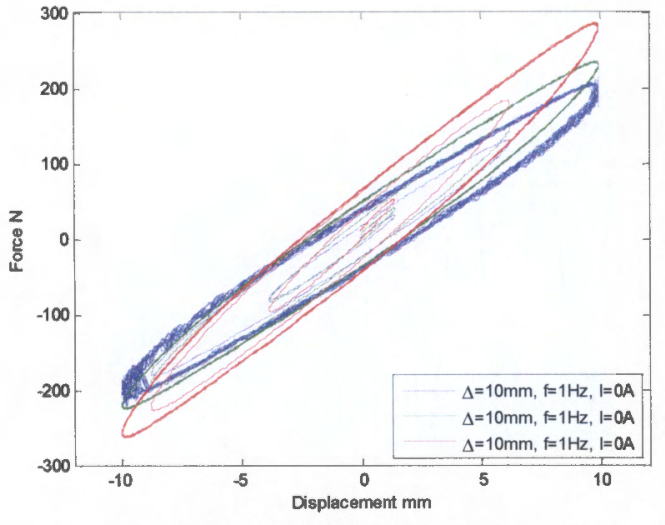

a) Force-displacement loops of MRE base isolator 1 at sinusoidal loading with $\Delta=10 \mathrm{~mm}$ and $\mathrm{f}=1.0 \mathrm{~Hz}$

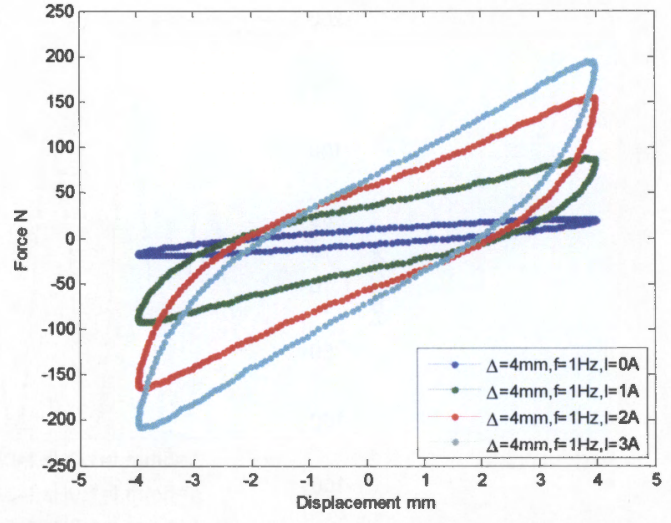

b) Force-displacement loops of MRE base isolator 2 at sinusoidal loading with $\Delta=4 \mathrm{~mm}$ and $\mathrm{f}=1.0 \mathrm{~Hz}$

Figure 10 Comparison between two MRE seismic isolator designs at moderate frequency excitations

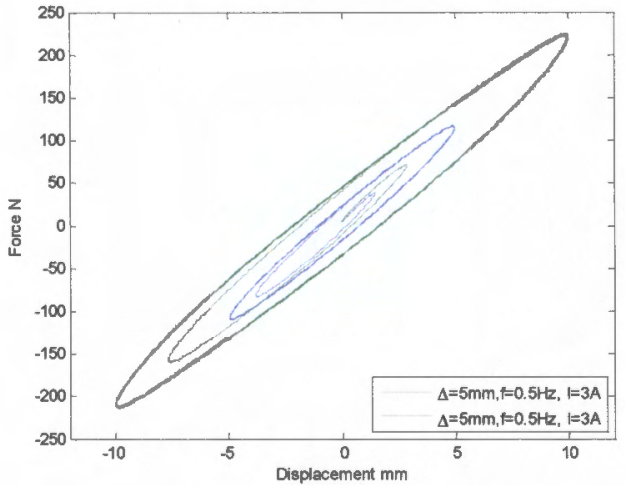

a) MRE seismic isolator prototype 1 at sinusoidal loading with $\mathrm{f}=0.5 \mathrm{~Hz}$ and $\mathrm{I}=3.0 \mathrm{~A}$

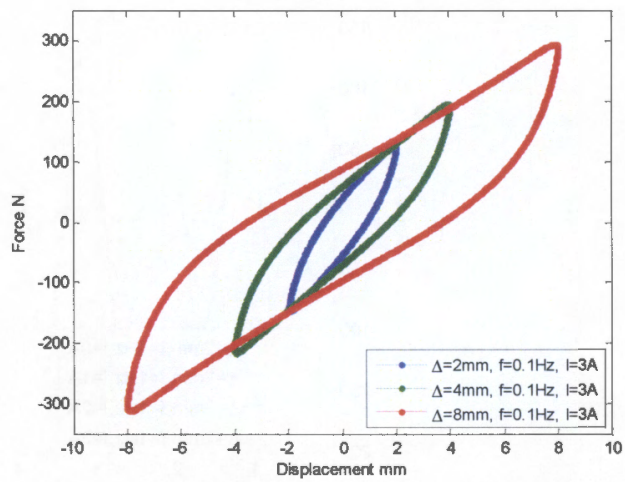

b) MRE seismic isolator prototype 2 at sinusoidal loading with $\mathrm{f}=0.1 \mathrm{~Hz}$ and $\mathrm{I}=3.0 \mathrm{~A}$

Figure 11Force-displacement loops of the MRE seismic isolators under low frequency excitations

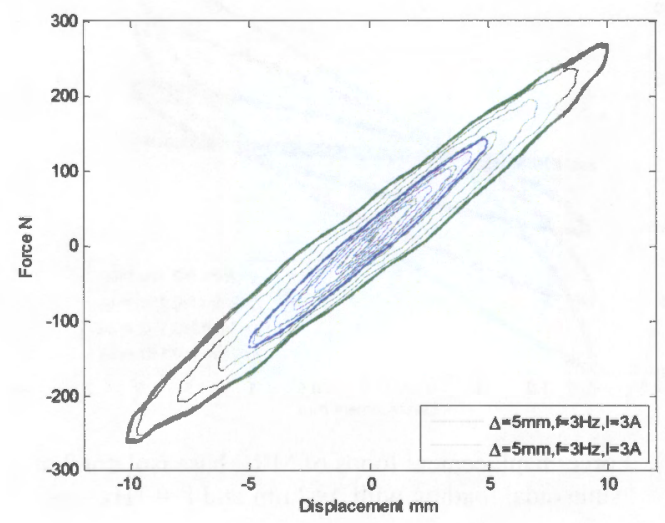

a) MRE seismic isolator prototype 1 at sinusoidal loading with $\mathrm{f}=3.0 \mathrm{~Hz}$ and $\mathrm{I}=3.0 \mathrm{~A}$

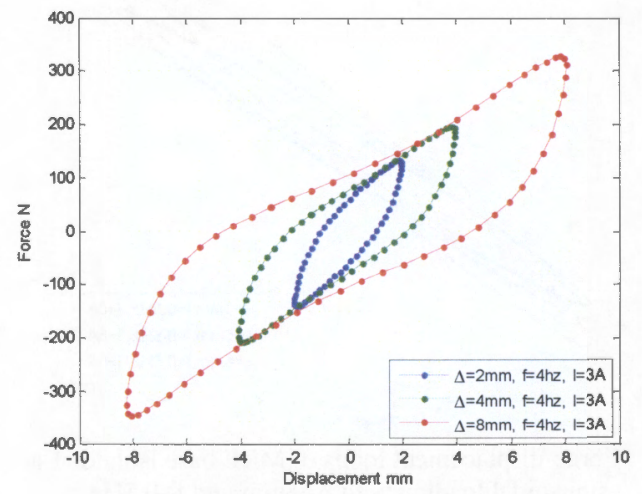

b) MRE seismic isolator prototype 2 at sinusoidal loading with $\mathrm{f}=4.0 \mathrm{~Hz}$ and $\mathrm{I}=3.0 \mathrm{~A}$

Figure 12 Force-displacement loops of the MRE seismic isolators under high frequency excitations 
It is also observed that for prototype 2, stiffness hardening appears when undergoes large deformations, i.e. $4 \mathrm{~mm}$ cases and all $8 \mathrm{~mm}$ cases, as shown in figure 11 and 12 . This phenomenon does not appear in prototype 1. Although quantitative analysis is not yet to be made to compare the performance of two devices taking into account of characteristics of the two materials, a general observation can be underpinned. For prototype 1, the displacements of $5 \mathrm{~mm}$ and $10 \mathrm{~mm}$, are still within small shear strain range, i.e. $5.3 \%$ and $10.6 \%$. For prototype 2 , the displacements of $2 \mathrm{~mm}, 4 \mathrm{~mm}$ and $8 \mathrm{~mm}$ equal to the shear strain of $8 \%, 16 \%$ and $32 \%$. It is well known that the stiffness hardening effect can only be observed in strain large deformation [30], although the critical deformation value may vary from one to another. For prototype 1, the largest deformation, $10 \mathrm{~mm}$, is assumed to be within the linear range of the material. For prototype 2, deformation of $8 \mathrm{~mm}$, producing shear strain of $32 \%$, is considered to be large.

Explanation for the strain hardening effect is attributed to the limited extensibility of the polymer chains [31] for normal rubber. However, for the field-dependent MR elastomer, it is much complex. As we know, the iron particles in the MR elastomer form chain-like structures after curing in a magnetic field for certain period, i.e. five days for the soft MRE sample in this research. When there is no magnetic field applied, the particles are restricted in the position due to the rubber matrix when the material undergoes shear deformation. When a certain level of magnetic field is applied to the material, besides the shear resistance comes from the rubber matrix, the iron particles are also held by the magnetic force from the surrounding iron particles, which make the extensibility of the chain structure even less. This may well be the reason that, for some cases at $4 \mathrm{~mm}$ amplitude testing, little strain hardening can be observed for zero magnetic field cases but is obvious for non-zero magnetic field cases.

Table 3. Maximum force $[\mathrm{N}]$ of the MRE seismic isolator prototype1 under various loading condition

\begin{tabular}{|c|c|c|c|c|c|c|}
\hline \multirow{2}{*}{ Maximum Force [N] } & \multicolumn{3}{|c|}{$\Delta=5 \mathrm{~mm}$} & \multicolumn{3}{c|}{$\Delta=\mathbf{1 0 \mathrm { mm }}$} \\
\cline { 2 - 7 } & $0.5 \mathrm{~Hz}$ & $1.0 \mathrm{~Hz}$ & $3.0 \mathrm{~Hz}$ & $0.5 \mathrm{~Hz}$ & $1.0 \mathrm{~Hz}$ & $3.0 \mathrm{~Hz}$ \\
\hline $0.0 \mathrm{~A}$ & 102.05 & 107.13 & 122.65 & 198.65 & 214.47 & 246.06 \\
\hline $3.0 \mathrm{~A}$ & 117.12 & 124.08 & 142.96 & 224.54 & 235.11 & 270.49 \\
\hline $5.0 \mathrm{~A}$ & 148.29 & 154.76 & 175.32 & 271.53 & 286.77 & 327.64 \\
\hline Increase (0.0-5.0A) & $\mathbf{4 5 . 3 1 \%}$ & $\mathbf{4 4 . 4 6 \%}$ & $\mathbf{4 2 . 9 4 \%}$ & $\mathbf{3 6 . 6 8} \%$ & $\mathbf{3 3 . 7 1 \%}$ & $\mathbf{3 3 . 1 5 \%}$ \\
\hline
\end{tabular}

Table 4Effective stiffness [ $\mathrm{kN} / \mathrm{m}]$ of the MRE seismic isolator prototypel under various loading condition

\begin{tabular}{|c|c|c|c|c|c|c|}
\hline \multirow{2}{*}{$\begin{array}{c}\text { Effective stiffness } \\
{[\mathbf{k N} / \mathbf{m}]}\end{array}$} & \multicolumn{3}{|c|}{$\Delta=\mathbf{5 m m}$} & \multicolumn{3}{c|}{$\Delta=\mathbf{1 0 m m}$} \\
\cline { 2 - 7 } & $0.5 \mathrm{~Hz}$ & $1.0 \mathrm{~Hz}$ & $3.0 \mathrm{~Hz}$ & $0.5 \mathrm{~Hz}$ & $1.0 \mathrm{~Hz}$ & $3.0 \mathrm{~Hz}$ \\
\hline $0.0 \mathrm{~A}$ & 19.73 & 20.91 & 24.22 & 18.58 & 19.53 & 23.42 \\
\hline $3.0 \mathrm{~A}$ & 22.24 & 23.61 & 27.38 & 21.62 & 22.77 & 26.03 \\
\hline $5.0 \mathrm{~A}$ & 27.13 & 28.59 & 32.51 & 25.59 & 26.92 & 30.4 \\
\hline Increase (0.0-5.0A) & $\mathbf{3 7 . 4 9} \%$ & $\mathbf{3 6 . 7 2} \%$ & $\mathbf{3 4 . 2 7} \%$ & $\mathbf{3 7 . 7 5} \%$ & $\mathbf{3 7 . 8 3} \%$ & $\mathbf{2 9 . 8 0 \%}$ \\
\hline
\end{tabular}

Table 5 Damping ratio [\%] of the MRE seismic isolator prototypel under various loading condition

\begin{tabular}{|c|c|c|c|c|c|c|}
\hline \multirow{2}{*}{ Damping ratio } & \multicolumn{3}{|c|}{$\Delta=5 \mathrm{~mm}$} & \multicolumn{3}{c|}{$\Delta=10 \mathrm{~mm}$} \\
\cline { 2 - 7 } & $0.5 \mathrm{~Hz}$ & $1.0 \mathrm{~Hz}$ & $3.0 \mathrm{~Hz}$ & $0.5 \mathrm{~Hz}$ & $1.0 \mathrm{~Hz}$ & $3.0 \mathrm{~Hz}$ \\
\hline $0.0 \mathrm{~A}$ & 0.0782 & 0.0841 & 0.0926 & 0.0904 & 0.1021 & 0.0983 \\
\hline $3.0 \mathrm{~A}$ & 0.0868 & 0.0918 & 0.0994 & 0.0905 & 0.0938 & 0.106 \\
\hline $5.0 \mathrm{~A}$ & 0.0895 & 0.0956 & 0.1062 & 0.0948 & 0.1005 & 0.1119 \\
\hline
\end{tabular}


The maximum force, effective stiffness and damping ratio calculated from the hysteresis loops of prototype 1 isolator are given in Table 3,4 and 5, respectively. For prototype 2 isolator the similar results are listed in Table 6, 7 and 8 . Under applied magnetic field, the prototype 1 can produce an increase on shear force up to $45.3 \%$ and in comparison the prototype 2 can produce a drastic increase on shear force up to $1479 \%$. In terms of maximum stiffness, prototype 1 is able to provide increase of stiffness up to $37.49 \%$, while prototype 2 generates increase up to $1630 \%$. With the increase of the excitation frequency and amplitude, the increase on both force and stiffness due to MR effect will decrease.

The MR effects result in damping ratio of prototype 1 isolator to increase from $7.82 \%$ to $11.19 \%$ and damping ratio of prototype 2 to increase from $15.1 \%$ to $27.6 \%$. Traditional laminated rubber bearing/isolators are generally categorized into two types: low damping rubber bearings and high damping rubber bearings. For low damping rubber bearings, the damping ratio is in the range of $2 \%-3 \%$ as being made of low damping natural rubber. While the damping ratio of high damping rubber bearing is up to $10 \%-15 \%$ of critical damping to serve the purpose of dissipating the vibration energy [1-3]. Comparing the damping characteristics of the prototypical MRE seismic isolators with traditional rubber bearing used in the base isolation practices, it can be seen that the first prototypical MRE seismic isolator, with damping ratio from $7.82 \%$ to $11.19 \%$ falls between low to medium damping rubber bearing category and the second prototypical MRE seismic isolator, with damping ratio from $15.1 \%$ to $27.6 \%$, clearly belongs to high damping rubber bearing class.

Table 6. Maximum forces $[\mathrm{N}]$ of the MRE seismic isolator prototype2under various loading conditions

\begin{tabular}{|c|c|c|c|c|c|c|c|c|c|c|c|c|}
\hline \multirow{2}{*}{$\begin{array}{c}\text { Maximum } \\
\text { force } \\
\text { (Normalised, } \\
\mathbf{N})\end{array}$} & \multicolumn{4}{|c|}{$\Delta=2 \mathrm{~mm}$} & \multicolumn{4}{|c|}{$\Delta=4 \mathrm{~mm}$} & \multicolumn{4}{|c|}{$\Delta=8 \mathrm{~mm}$} \\
\hline & $0.1 \mathrm{~Hz}$ & $1 \mathrm{~Hz}$ & $2 \mathrm{~Hz}$ & $4 \mathrm{~Hz}$ & $0.1 \mathrm{~Hz}$ & $1 \mathrm{~Hz}$ & $2 \mathrm{~Hz}$ & $4 \mathrm{~Hz}$ & $0.1 \mathrm{~Hz}$ & $1 \mathrm{~Hz}$ & $2 \mathrm{~Hz}$ & $4 \mathrm{~Hz}$ \\
\hline $0.0 \mathrm{~A}$ & 8.13 & 10.93 & 12.72 & 15.58 & 15.17 & 20.12 & 23.56 & 28.98 & 30.59 & 39.70 & 45.41 & 55.66 \\
\hline $1.0 \mathrm{~A}$ & 52.70 & 56.99 & 57.69 & 59.86 & 79.39 & 86.63 & 88.26 & 92.33 & 131.48 & 148.36 & 150.71 & 160.53 \\
\hline $2.0 \mathrm{~A}$ & 93.78 & 106.77 & 104.58 & 106.88 & 138.38 & 156.79 & 155.32 & 159.11 & 224.01 & 260.03 & 261.04 & 272.32 \\
\hline $3.0 \mathrm{~A}$ & 128.39 & 136.20 & 133.25 & 135.78 & 190.48 & 199.79 & 197.48 & 201.67 & 298.29 & 323.10 & 326.01 & 338.51 \\
\hline $\begin{array}{c}\text { Increase }(0 \mathrm{~A}- \\
3 \mathrm{~A})\end{array}$ & $1479 \%$ & $1146 \%$ & $948 \%$ & $772 \%$ & $1156 \%$ & $993 \%$ & $738 \%$ & $596 \%$ & $875 \%$ & $714 \%$ & $618 \%$ & $508 \%$ \\
\hline
\end{tabular}

Table 7. Effective stiffness $[\mathrm{kN} / \mathrm{m}]$ of the MRE seismic isolator prototype 2 under various loading conditions

\begin{tabular}{|c|c|c|c|c|c|c|c|c|c|c|c|c|}
\hline \multirow{2}{*}{$\begin{array}{c}\text { Effective stiffness } \\
\text { (Normalised, } \\
\text { kN/m) }\end{array}$} & \multicolumn{4}{|c|}{$\Delta=2 \mathrm{~mm}$} & \multicolumn{4}{|c|}{$\Delta=4 \mathrm{~mm}$} & \multicolumn{4}{|c|}{$\Delta=8 \mathrm{~mm}$} \\
\hline & $0.1 \mathrm{~Hz}$ & $1 \mathrm{~Hz}$ & $2 \mathrm{~Hz}$ & $4 \mathrm{~Hz}$ & $0.1 \mathrm{~Hz}$ & $1 \mathrm{~Hz}$ & $2 \mathrm{~Hz}$ & $4 \mathrm{~Hz}$ & $0.1 \mathrm{~Hz}$ & $1 \mathrm{~Hz}$ & $2 \mathrm{~Hz}$ & $4 \mathrm{~Hz}$ \\
\hline $0.0 \mathrm{~A}$ & 3.64 & 4.96 & 5.80 & 6.88 & 3.63 & 4.69 & 5.33 & 6.43 & 3.72 & 4.62 & 5.24 & 6.23 \\
\hline $1.0 \mathrm{~A}$ & 25.58 & 27.13 & 27.52 & 27.75 & 19.35 & 20.72 & 20.87 & 21.07 & 15.99 & 17.72 & 17.81 & 18.12 \\
\hline $2.0 \mathrm{~A}$ & 45.73 & 52.22 & 50.64 & 50.47 & 33.73 & 38.15 & 37.53 & 37.25 & 27.32 & 31.44 & 31.15 & 31.30 \\
\hline $3.0 \mathrm{~A}$ & 62.98 & 66.13 & 65.02 & 65.26 & 46.64 & 48.74 & 47.88 & 47.72 & 36.41 & 39.31 & 39.29 & 39.30 \\
\hline Increase $(0 A-3 A)$ & $\begin{array}{c}1630 \\
\%\end{array}$ & $\begin{array}{c}1234 \\
\%\end{array}$ & $1022 \%$ & $\begin{array}{c}848 \\
\% \\
\end{array}$ & $\begin{array}{c}1186 \\
\%\end{array}$ & $939 \%$ & $798 \%$ & $\begin{array}{c}642 \\
\%\end{array}$ & $\begin{array}{c}878 \\
\%\end{array}$ & $751 \%$ & $\mathbf{6 5 0} \%$ & $\begin{array}{c}\mathbf{5 3 1} \\
\% \\
\end{array}$ \\
\hline
\end{tabular}

Table 8. Damping ratio of the MRE seismic isolator prototype2under various loading conditions

\begin{tabular}{|c|c|c|c|c|c|c|c|c|c|c|c|c|}
\hline \multirow{2}{*}{$\begin{array}{c}\text { Damping Ratio } \\
\text { (normalised kN.s/m) }\end{array}$} & \multicolumn{4}{|c|}{$\Delta=\mathbf{m m}$} & \multicolumn{4}{c|}{$\Delta=4 \mathrm{~mm}$} & \multicolumn{4}{c|}{$\Delta=8 \mathrm{~mm}$} \\
\cline { 2 - 13 } & $0.1 \mathrm{~Hz}$ & $1 \mathrm{~Hz}$ & $2 \mathrm{~Hz}$ & $4 \mathrm{~Hz}$ & $0.1 \mathrm{~Hz}$ & $1 \mathrm{~Hz}$ & $2 \mathrm{~Hz}$ & $4 \mathrm{~Hz}$ & $0.1 \mathrm{~Hz}$ & $1 \mathrm{~Hz}$ & $2 \mathrm{~Hz}$ & $4 \mathrm{~Hz}$ \\
\hline $0.0 \mathrm{~A}$ & 0.151 & 0.220 & 0.243 & 0.258 & 0.145 & 0.223 & 0.249 & 0.266 & 0.127 & 0.205 & 0.232 & 0.254 \\
\hline $1.0 \mathrm{~A}$ & 0.214 & 0.240 & 0.250 & 0.276 & 0.202 & 0.228 & 0.244 & 0.277 & 0.183 & 0.204 & 0.222 & 0.254 \\
\hline $2.0 \mathrm{~A}$ & 0.207 & 0.218 & 0.233 & 0.252 & 0.193 & 0.206 & 0.220 & 0.246 & 0.177 & 0.188 & 0.202 & 0.226 \\
\hline $3.0 \mathrm{~A}$ & 0.183 & 0.201 & 0.212 & 0.229 & 0.175 & 0.189 & 0.201 & 0.223 & 0.173 & 0.179 & 0.188 & 0.210 \\
\hline
\end{tabular}




\section{CONCLUSION}

This paper presented recent development on a novel adaptive seismic isolator utilizing field-dependent MRE material which addresses the challenge existing in current base isolation system, i.e. passive nature without adaptability to different external excitations. A unique design with laminated steel and MRE layers is adopted to offer high vertical loading capacity and low lateral stiffness. Discussion on the optimal design of such adaptive seismic isolator was made and trade-off among the initial weight capacity, lateral stiffness requirement and the adaptive range were carefully considered in the design. Comprehensive experimental investigations were conducted to validate and examine dynamic performances of the MRE isolators. Experimental results showed that the first prototypical MRE seismic isolator can produce increases on shear force up to $45.3 \%$ and increases on stiffness up to $37.49 \%$, while the $2^{\text {nd }}$ prototypical MRE seismic isolator produced amazing increase on shear force up to $1479 \%$ and on stiffness up to $1630 \%$. With the development of such adaptive seismic isolators, controlling a base isolation system to alter its resonant frequency in real time is no longer hypothetical.

To conclude, the development of novel adaptive seismic isolators was realized via incorporating field-dependent MRE material into seismic isolator design. Two prototypical seismic isolators, one with large initial loading capacity but small adjustable lateral stiffness (up to $37.49 \%$ ) and the other with small initial loading capacity but large adjustable lateral stiffness (up to $1630 \%$ ) are designed, fabricated and tested. Due to their passive nature, the traditional seismic base isolation systems, once designed and installed (for the targeted isolation frequency range and displacement), can only passively react whatever happens to them. On the other hand, the developed adaptive seismic isolator possesses ability to change targeted isolation frequency range instantly. It therefore can be used for semi-active control or smart passive control to alter isolation frequency by changing stiffness of the seismic isolators or to alter damping of the system or both. The success on the development and experimental evaluation of the prototypes of the laminated MRE seismic isolators reported in this paper has offered solution to overcome the inherent shortcomings of the traditional seismic base isolation system and provided an opportunity for create intelligent and adaptive seismic isolation system which is capable to combat all types of earthquakes.

\section{REFERENCES}

[1] Naeim, F. and Kelly, J. M., 1999 [Design of seismic isolated structures: from theory to practice], John Wiley and Sons, Hoboken, NJ, 1-93 (1999).

[2] Komodromos, P., [Seismic isolation for earthquake resistant structures], WIT Press, Southampton, UK, 1-120 (2001)

[3] Kelly, J. M., "Base isolation: linear theory and design," Earthq. Spectra 6, 223-244 (1990).

[4] Kelly, J. M., "The current state of base isolation in the United States," 2nd world conf. struct. Contr. 1043-1052 (1999).

[5] Kelly, J, M., "Seismic Isolation Systems for Developing Countries," Earthq. Spectra 18, 385-406 (2002).

[6] Morgan, T. A., "The use of innovative base isolation systems to achieve complex seismic performance objectives," PhD Dissertation, University of California, Berkeley, 7-51 (2007).

[7] Pan, P., Zamfirescu, D., Nakashima, M., Nakayasu, N. and Kashiwa, H., "Base-isolation design practice in Japan: introduction to the post-Kobe approach," J. Earthquake Eng. 9, 147-171 (2005).

[8] Yoshioka, H., Ramallo, J. C. and Spencer, B. F. Jr., "'Smart' Base Isolation Strategies Employing Magnetorheological Dampers," J. Eng. Mech.128 540-551 (2002).

[9] Ramallo, J. C., Johnson, E. A. and Spencer, B. F. Jr., "'Smart' Base Isolation Systems," J. Eng. Mech. 128, 10881099 (2002).

[10] Spencer, B. F. and Nagarajaiah, S., "State of the Art of Structural Control," J. Struc. Eng. 129, 845-856 (2003).

[11] Jangid, R. S. and Kelly, J. M., "Base isolation for near-fault motions," Earthq. Eng. Struct. Dyn. 30, 691-707 (2001). 
[12] Mazza, F. and Vulcano, A., "Effects of near-fault ground motions on the nonlinear dynamic response of baseisolated R C framed buildings," Earthq. Eng. Struct. Dyn. 41, 211-232 (2012).

[13] Nagarajaiah, S., "Structural Control Benchmark Problem Smart Base Isolated Building Subjected to Near Fault Earthquakes," Struct. Contr. Health Monit. 13, 653-656 (2006).

[14]Chopra, A. K. and Chintanapakdee, C., "Comparing response of SDF systems to near-fault and far-fault earthquake motions in the context of spectral regions," Earthq. Eng. Struct. Dyn. 30, 1769-1789 (2001).

[15] Abdalla, J. A., Petrovski, J. T. and Mohamedzein, Y. E-A., "Vibration Characteristics of A Far-Field Earthquake and its Shaking Effects on Dubai Emerging Skycrapers," The 14th World Conf. Earthq. Eng. Paper 145, (2008)

[16]Kelly J M 1991 Base Isolation: Origins and Development EERC News

[17] Ronbinson, W. H., "Lead-Rubber hysteretic bearings suitable for protecting structures during earthquakes," Earthq. Eng. Struct. Dyn. 10, 593-604 (1982).

[18] Fuller, K. N. G., Gough, J., Pond, T. J. and Ahmadi, H. R., "High damping natural rubber seismic isolators," J. Struct. Contr. 4, 19-40 (1997).

[19] Lu, Lyan-Ywan and Lin, Ging-Long, "Fuzzy Friction Controllers for Semi-active Seismic Isolation Systems," J. Intell. Mater. Syst. Struct. 20, 1747-1770 (2009).

[20] Wongprasert, N. and Symans, M. D., "Experimental evaluation of adaptive elastomeric base-isolated structures using variable-orifice fluid dampers," J. Struct. Eng. 131, 867-877 (2005).

[21] Yang, J. N. and Agrawal, A. K., "Semi-active hybrid control systems for nonlinear buildings against near-field earthquakes," Eng. Struct. 20, 271-280 (2002).

[22] Lin, P. Y., Roschke, P. N. and Loh, C. H., "Hybrid Base isolation with Magneto-rheological Damper and Fuzzy Control," Struct. Contr. Health Monit. 14, 384-405 (2007b).

[23] Kim, H. S., Roschke, P. N., Lin, P. Y. and Loh, C. H., "Neuro-fuzzy Model of Hybrid Semi-active Base Isolation System with FPS Bearings and an MR Damper," Eng. Struc. 28, 947-958 (2006).

[24] Popp, K., Kroger, M., Li, W., Zhang, X. and Kosasih, P., "MRE Properties under shear and squeeze modes and applications," J. Intell. Mater. Syst. Struct. 21, 1471-1477(2010).

[25] Li, W., Zhou, Y. and Tian, T., "Viscoelastic properties of MR elastomers under harmonic loading," Rheol. Acta 49 733-740 (2010).

[26] Li, W. H., Zhang, X. Z., Du, H. and Chen, D. F., 2006 "Enhance MR elastomer performance with nano-particles additives," The 3rd Asia-Pacific Conf. Transducers and Micro/Nanotechnology, (2006).

[27] Kallio, M., Lindroos, T., Aalto, S., Jarvinen, E., Karna, T. and Meinander, T., "Dynamic compression testing of a tunable spring element consisting of a magnetorheological elastomer," Smart Mater. Struct. 16, 506-514 (2007).

[28]Li, Y., Li, J., Li, W. and Samali, B., "Development and characterization of a magnetorheological elastomer based adaptive seismic isolator," Smart Mater. Struct. 22, 035005 (2013).

[29] Li, J., Li, Y. and Samali, B., "Adaptive MRE Vibration Isolation Assembly and System," Australian Provisional Patent No. 2012904337 (2012).

[30]Bergstom, J. S. and Boyce, M. C., "Large strain time-dependent behavior of filled elastomers," Mech. Mater. 32 , 627-644 (2000).

[31] Spathis, G. and Kontou, E., "Modeling of nonlinear viscoelasticity at large deformations," J Mater Sci 43, 20462052 (2008). 